\title{
The current status of watchful waiting for inguinal hernia management: a review of clinical evidence
}

\author{
Patrick J. McBee ${ }^{1}$, Robert J. Fitzgibbons, Jr $^{2}$ \\ ${ }^{1}$ Creighton University School of Medicine, Omaha, NE 68178, USA. \\ ${ }^{2}$ Department of Surgery, Creighton University Medical Center, Omaha, NE 68131, USA.
}

Correspondence to: Dr. Robert J. Fitzgibbons, Jr, Department of Surgery, Creighton University Medical Center, Creighton University Education Building 7710 Mercy Road, Suite 501 Omaha, Nebraska 68124, USA. E-mail: fitzjr@creighton.edu

How to cite this article: McBee PJ, Fitzgibbons, Jr RJ. The current status of watchful waiting for inguinal hernia management: a review of clinical evidence. Mini-invasive Surg 2021;5:18. https://dx.doi.org/10.20517/2574-1225.2021.08

Received: 22 Jan 2021 First Decision: 15 Feb 2021 Revised: 21 Feb 2021 Accepted: 25 Feb 2021 Available online: 17 Apr 2021

Academic Editor: William W. Hope Copy Editor: Yue-Yue Zhang Production Editor: Yue-Yue Zhang

\begin{abstract}
Inguinal hernias are a very common problem and the most common reason for primary care physicians to refer patients for surgery. The diagnosis is usually made from history and physical examination and men are significantly more likely to be affected than women. Most patients will present with a painful bulge in the groin, though up to a third of patients will be asymptomatic at the time of diagnosis. Previously, it had been recommended that all hernias be repaired surgically at the time of diagnosis to prevent the development of a hernia accident (bowel obstruction or strangulation) that would require emergent surgery, which is associated with much higher morbidity and mortality than an elective repair. However, several clinical trials have reported that risks of a hernia accident are sufficiently low so that a "watchful waiting" (WW) approach for male patients who are asymptomatic or minimally symptomatic is a safe management strategy. WW spares patients any risk of operative complications related to their herniorrhaphy, perhaps the most significant of which is post-herniorrhaphy groin pain that has only recently been appreciated as a significant issue. Although WW has now been proven to be safe in asymptomatic males with an inguinal hernia, long-term results of randomized controlled trials have shown that most patients initially managed with WW will eventually elect to have the hernia surgically repaired primarily due to increased pain. The purpose of this article is to review the current evidence on watchful waiting for the management of inguinal hernias.
\end{abstract}

Keywords: Inguinal hernia, watchful waiting, groin hernia, herniorrhaphy 


\section{INTRODUCTION}

Groin hernias are a very common problem with presentation ranging from patients who are completely asymptomatic to those with the life-threatening complication of strangulation or bowel obstruction, referred to as a hernia accident. Over 1.6 million hernias are diagnosed each year in the United States alone, of which 500,000 are surgically repaired ${ }^{[1]}$. Of the groin hernias in the United States, 96\% are classified as inguinal hernias and $4 \%$ are femoral ${ }^{[2]}$. Men are significantly more likely to develop a groin hernia than women; the lifetime risk of is $27 \%$ for men and $3 \%$ for women ${ }^{[1]}$. Two-thirds of patients will present with a painful bulge in the groin and diagnosis is made primarily through history and physical examination with imaging rarely required ${ }^{[3]}$. Up to one third of inguinal hernia patients present asymptomatically without pain or other factors that lead to impairment of daily functioning ${ }^{[4]}$.

Management of inguinal hernias has evolved over time to improve quality of life and limit safety risk to the patient. Historically, it was recommended that all patients presenting with an inguinal hernia have it repaired surgically at the time of diagnosis due to the prevailing belief that the risk of a hernia accident (bowel obstruction and/or strangulation) was significantly high enough to contraindicate watchful waiting (WW). However, more recent evidence of WW has emerged that has shown that WW is a safe and acceptable alternative to surgical repair for asymptomatic or minimally symptomatic inguinal hernia patients. Avoiding operative repair in asymptomatic patients through a WW approach precludes any potential development of pain related to the operation as well as the other standard risks associated with major surgery (e.g., hemorrhage, infection, and recurrence). Post-herniorrhaphy groin pain has now come to the forefront of issues facing groin hernia surgeons as some studies suggest that as many as $15 \%$ of patients experience post-herniorrhaphy inguinal groin pain that affects their daily lives 6 months after the operation $^{[5]}$.

To date, three major clinical trials from North America, the United Kingdom and the Netherlands have investigated outcomes after randomization of patients presenting with asymptomatic or minimally symptomatic inguinal hernias to a WW approach vs. routine elective surgical repair ${ }^{[6-8]}$. While all completed trials support WW as a viable and safe approach for some patients in the initial treatment of inguinal hernia management, long-term follow-up has found that most (approximately 70\%) of patients who elect to forego hernia repair will eventually be treated surgically due to worsening pain or lifestyle limitations from progression of symptoms. The purpose of this article is to provide an overview of the current status of watchful waiting as an option for initial inguinal hernia management and review the clinical evidence from randomized controlled trials that led to the adaptation of WW as an acceptable alternative to an operative approach.

\section{WATCHFUL WAITING}

The risks and benefits of WW as an approach for inguinal hernia management in patients who are asymptomatic or mildly symptomatic were investigated in three randomized controlled trials from North America, the UK, and the Netherlands. Asymptomatic or minimally symptomatic patients were defined as those patients whose hernia-related discomfort did not limit activities of daily living and who did not exhibit difficulty in manually reducing the hernia ${ }^{[6]}$. An important distinction is necessary to recognize in the optimal management of hernias between men and women. Currently, the approach of WW is only an appropriate strategy for men because women are significantly more likely to develop femoral hernias, which are more prone to strangulation ${ }^{[9]}$. It is difficult to distinguish inguinal hernias from femoral hernias, so surgical repair is recommended for all nonpregnant women with groin hernias ${ }^{[10]}$. Pregnant women with a groin bulge which appears to be a hernia should be imaged with ultrasound to rule out round ligament varicosities, a common cause of a groin bulge in a pregnant female, before surgery is considered ${ }^{[10]}$. 


\section{NORTH AMERICAN TRIAL}

A randomized control trial with 720 men, 18 years of age or older with inguinal hernias who presented asymptomatically or with minimal symptoms was completed in North America in 2006, showing WW as a safe alternative to surgical repair ${ }^{[6]}$. Patients were assigned to either a WW or a Lichtenstein repair approach and followed to observe differences in development of a hernia accident between the two groups. Patients were similar at baseline in terms of age, American Society of Anesthesiology classification, preexisting conditions, hernia type, and hernia characteristics. At 2 years of follow-up, only 1 patient (0.3\%) required emergent surgery for an acute hernia incarceration and the patient was not found to have strangulation. There was no difference in quality of life between the two groups at 2 years. Patients in the WW group crossed over to the surgical repair group at a rate of $23 \%$, most commonly due to pain, and were more likely to do so if they had reported higher levels of pain at the start of the trial. At 4.5 years of follow-up, only one additional patient in the WW group developed acute incarceration with bowel obstruction, for a total surgical emergency rate of 1.8 per 1000 person-years at the end of the trial. Although this study clearly showed that WW was a safe alternative to routine repair for minimally symptomatic males, subsequent long-term follow-up at 10 years showed that $68 \%$ of patients originally in the WW group had crossed over to surgical repair, mostly due to increased pain ${ }^{[1]}$. The authors recommended that men with minimally symptomatic inguinal hernias be informed that WW is a safe preliminary management choice to avoid immediate operative intervention but most individuals will eventually undergo surgical repair if they live long enough.

\section{UNITED KINGDOM TRIAL}

In this trial, 160 men aged 55 years or older with minimally symptomatic inguinal hernias were enrolled in a single-center randomized controlled trial to investigate WW vs. surgical repair ${ }^{[7]}$. At one year of follow-up, there were no significant differences in pain scores between the watchful waiting and surgical repair cohorts, although the surgical repair group did report improvement in their perceived quality of life. The crossover rate from WW to surgery was $29 \%$ at one year, with increasing pain and enlargement of the hernia responsible for most cases of crossover. The incidence of serious events in the WW group was minimal; one patient developed a hernia incarceration and two others experienced cardiovascular events after crossover to the repair group. The authors hypothesized that the cardiovascular complications could have been prevented had the patients undergone surgical repair at the start of the trial, but this has been criticized by other authorities as highly speculative ${ }^{[12]}$. Similar to the North American Trial, long-term follow-up disclosed a high crossover rate to surgery ( $72 \%$ at 7.5 years by Kaplan-Meier analysis), demonstrating that for most patients who present with an inguinal hernia, surgical repair will eventually become necessary ${ }^{[13]}$.

\section{NETHERLANDS TRIAL}

In 2018, researchers in the Netherlands reported results from a multicenter randomized controlled trial to determine the noninferiority of WW compared to elective hernia repair in 496 men aged 50 years or older who presented with mildly symptomatic or asymptomatic inguinal hernias ${ }^{[8]}$. The primary outcome measure was pain and discomfort at 2 years of follow-up using a 4-point pain/discomfort score which ranged from no pain or discomfort to severe pain or discomfort due to the hernia while working, exercising or performing any of a patient's usual activities. Secondary endpoints included: health-related quality of life as measured by the Short-Form 36 (SF-36) questionnaire, overall 3-year crossover rate in patients assigned to watchful waiting, 3-year event-free survival between the 2 treatment groups, hernia complication (incarceration or strangulation), ischemic orchitis, and recurrent hernia. The EuroQol-5D (EQ-5D) questionnaire was also assessed at baseline, 3, 12, 24, and 36 months. The EQ-5D included a visual analog scale (VAS) to rate overall health status on a scale of o (worst imaginable health state) to 100 (best 
imaginable health state). The patient pain/discomfort score was found to be 0.35 [95\% confidence interval (CI): 0.28-0.41)] in the elective repair group and 0.58 (95\%CI: 0.52-0.64) in the WW group. The difference of these means (MD) was - 0.23 (95\%CI: 0.32-0.14), showing that a relevant difference in favor of elective repair could not be ruled out. Ninety-nine patients $(37.8 \%)$ crossed over from the WW cohort to surgical repair, mostly due to worsening pain. Six patients (2.3\%) underwent emergent surgery for strangulation or incarceration but none suffered adverse sequelae such as the need for bowel resection after three years of follow-up. The 3-year event-free survival was $80.9 \%$ in the surgical repair group and $77.2 \%$ in the WW group. The cumulative incidence of patients with at least one or more events (recurrence, moderate to severe pain, ischemic orchitis, hernia complications, etc.) in the surgery repair and WW groups was 17.5\% and $20.6 \%$, respectively at three years. Although a statistically significant advantage for WW over routine repair was not demonstrated, the authors concluded that when looking at the primary and secondary endpoints as a whole, watchful waiting was a reasonable alternative compared with routine elective surgery in male patients. Due to the recency of the trial's completion, long-term analysis is not yet available.

\section{SIMILARITIES BETWEEN TRIALS}

Generally, all three trials reached the same conclusion: WW is a safe and appropriate strategy for initial management of inguinal hernia in male patients who present with minimal or no symptoms. The previous belief held by many surgeons that a significant proportion of patients not treated by surgical repair upon presentation would suffer a hernia accident which would result in a significant increase in morbidity and mortality was not supported. Few patients in the WW cohorts exhibited serious hernia accidents in shortand long-term follow-up. Table 1 describes notable findings across all three clinical trials. The trials concluded that potential future risk of a hernia accident should not contribute to an indication for surgical repair. Instead, relief of symptoms such as pain and other issues related to improvement of quality of life should be used as the metric to pursue surgical intervention. In the two studies with long-term results, the rate of crossover from WW to surgical repair was high (approximately 70\%) due mostly to development of worsening pain.

Gong and colleagues recently performed a meta-analysis which included the short- and long-term followup data from the North American, UK, and Netherlands trials ${ }^{[14]}$. Patients who underwent surgical repair reported significantly less pain with movement at a minimum of 12-month follow-up. However, there was no significant difference in the physical component score, mortality, surgical complications, or postoperative hernia recurrence between the WW and surgical repair groups. The meta-analysis confirmed that most patients will undergo an elective hernia repair operation within 10 years of presentation. Regardless, due to the low incidence of hernia accidents, the meta-analysis concluded that WW is a safe and acceptable option in short-term management of inguinal hernias in men. The authors also noted that WW provides a delay in surgery if desired but does not prevent relatively inevitable repair. Similar conclusions were reached by Reistrup ${ }^{[15]}$ and colleagues who recently published a systematic review of randomized and nonrandomized RCTs investigating watchful waiting.

\section{TRIAL LIMITATIONS}

Similar limitations were exhibited by all three clinical trials: generalizability, sample size, and length of follow-up. Most trial participants were white males, limiting extrapolation to patients of differing races and sexes. The authors of all trials reported that recruiting patients was difficult with only $45 \%$ and $69 \%$ of eligible patients agreeing to randomization in the North American and UK trials, respectively.

Additionally, it is important to note that clinical trials in low- and middle income countries are currently lacking. All trials completed to date are from high income countries, despite evidence that most hernias 
Table 1. Comparison of Watchful Waiting Randomized Controlled Trials

\begin{tabular}{|c|c|c|c|c|c|c|c|c|}
\hline \multirow[b]{2}{*}{ Trial Location } & \multirow{2}{*}{$\begin{array}{l}\text { Sample } \\
\text { Size }\end{array}$} & \multirow[b]{2}{*}{ Age } & \multicolumn{3}{|c|}{ Short-Term } & \multicolumn{3}{|c|}{ Long-Term } \\
\hline & & & Follow-up & $\begin{array}{l}\text { Crossover } \\
\text { rate }\end{array}$ & $\begin{array}{l}\text { Hernia } \\
\text { Accidents }\end{array}$ & Follow-up & $\begin{array}{l}\text { Crossover } \\
\text { rate }\end{array}$ & $\begin{array}{l}\text { Hernia } \\
\text { Accidents }\end{array}$ \\
\hline $\begin{array}{l}\text { North American } \\
\text { Trial }\end{array}$ & 720 & $\begin{array}{l}\geq 18 \text { (mean } \\
58)\end{array}$ & $\begin{array}{l}3.2 \text { years, } \\
\text { mean }\end{array}$ & $23 \%$ at 2 years & $0.6 \%(n=2)$ & $\begin{array}{l}11.5 \text { years } \\
(\max )\end{array}$ & $\begin{array}{l}68 \% \text { at } 10 \\
\text { years }\end{array}$ & $1.2 \%(n=3)$ \\
\hline $\begin{array}{l}\text { United Kingdom } \\
\text { Trial }\end{array}$ & 160 & $\begin{array}{l}>55 \text { (mean } \\
70)\end{array}$ & $\begin{array}{l}1.6 \text { years, } \\
\text { median }\end{array}$ & $29 \%$ & $1.3 \%(n=1)$ & $\begin{array}{l}7.5 \text { years } \\
\text { (median) }\end{array}$ & $\begin{array}{l}72 \% \text { at } 7.5 \\
\text { years }\end{array}$ & $2.5 \%(n=2)$ \\
\hline Netherlands Trial & 496 & $\begin{array}{l}>50 \text { (mean } \\
65)\end{array}$ & 3 years & $38 \%$ & $2.3 \%(n=6)$ & NA & NA & NA \\
\hline
\end{tabular}

worldwide occur in low-income countries and present at a later stage compared to those in developed countries. For example, in Guatemala one study suggested that as many as $25 \%$ of hernia cases may present at an emergent stage and that patient-related issues (i.e., lack of transport and follow-up) contribute greatly to significant delays in treatment ${ }^{[16]}$. Thus, clinical trials completed in developed countries may fail to capture the total impact of hernia-related disease burden on patients in low-income countries.

\section{CONCLUSION}

Watchful waiting is a safe and appropriate early management strategy for male patients who present with asymptomatic or minimally symptomatic inguinal hernias. The risk of serious incarceration or strangulation is sufficiently low with an approach of watchful waiting. However, patients need to be informed that they will more likely elect to undergo surgical repair within a decade of diagnosis due to worsening pain. By delaying surgical intervention in patients with fewer or no complaints of pain, specific surgical complications such as post-herniorrhaphy inguinal groin pain that affect a minority of patients as well as the other common risks of surgery can be avoided, keeping in mind the overall incidences of pain in both the WW and surgical groups are the same. Our article has summarized the evidence obtained by three clinical trials in North America, the UK, and the Netherlands that support pursuing a watchful waiting strategy. We acknowledge that there is a concern on the part of some surgeons that patients will develop comorbidities with a WW approach, which may result in making these patients poor operative candidates. However, with the exception of a small number of patients from the UK trial who experienced cardiovascular symptoms, the majority of data from most trials do not support this notion. It is important to emphasize that these data apply only to males and that WW should not be extrapolated to females because the natural history of femoral hernias is different for males. Routine elective repair is still recommended in females.

\section{DECLARATIONS}

\section{Authors' contributions}

Made substantial contributions to overall concept and design of article: Fitzgibbons RJ, McBee PJ

Performed literature review: McBee PJ

Wrote text of manuscript: McBee PJ, Fitzgibbons RJ Jr

Edited manuscript: Fitzgibbons RJ Jr

\section{Availability of data and materials}

Not applicable.

\section{Financial support and sponsorship}

None. 


\section{Conflicts of interest}

All authors declared that there are no conflicts of interest.

\section{Ethical approval and consent to participate}

Not applicable.

\section{Consent for publication}

Not applicable.

\section{Copyright}

(C) The Author(s) 2021.

\section{REFERENCES}

1. Cullen KA, Hall MJ, Golosinskiy A. Ambulatory surgery in the United States, 2006. Natl Health Stat Report 2009;(11):1-25. PubMed

2. Bax T, Sheppard BC, Crass RA. Surgical options in the management of groin hernias. Am Fam Physician 1999;59:893-906. PubMed

3. Kraft BM, Kolb H, Kuckuk B, et al. Diagnosis and classification of inguinal hernias. Surg Endosc 2003;17:2021-4. DOI PubMed

4. Hair A, Paterson C, Wright D, Baxter JN, O'dwyer PJ. What effect does the duration of an inguinal hernia have on patient symptoms? J Am Coll Surg 2001;193:125-9. DOI PubMed

5. Andresen K, Burcharth J, Fonnes S, et al. Chronic pain after inguinal hernia repair with the ONSTEP versus the Lichtenstein technique, results of a double-blinded multicenter randomized clinical trial. Langenbecks Arch Surg 2017;402:213-8. DOI PubMed

6. Fitzgibbons RJ Jr, Giobbie-Hurder A, Gibbs JO, et al. Watchful waiting vs repair of inguinal hernia in minimally symptomatic men: a randomized clinical trial. JAMA 2006;295:285-92. DOI PubMed

7. O'Dwyer PJ, Norrie J, Alani A, Walker A, Duffy F, Horgan P. Observation or operation for patients with an asymptomatic inguinal hernia: a randomized clinical trial. Ann Surg 2006;244:167-73. DOI PubMed PMC

8. Goede B, Wijsmuller AR, van Ramshorst GH, et al; INCA Trialists' Collaboration. Watchful Waiting Versus Surgery of Mildly Symptomatic or Asymptomatic Inguinal Hernia in Men Aged 50 Years and Older: A Randomized Controlled Trial. Ann Surg 2018;267:42-9. DOI PubMed

9. Koch A, Edwards A, Haapaniemi S, Nordin P, Kald A. Prospective evaluation of 6895 groin hernia repairs in women. $B r J$ Surg 2005;92:1553-8. DOI PubMed

10. Group. International guidelines for groin hernia management. Hernia 2018;22:1-165. DOI PubMed PMC

11. Fitzgibbons RJ Jr, Ramanan B, Arya S, et al; Investigators of the Original Trial. Long-term results of a randomized controlled trial of a nonoperative strategy (watchful waiting) for men with minimally symptomatic inguinal hernias. Ann Surg 2013;258:508-15. DOI PubMed

12. Turaga K, Fitzgibbons RJ Jr, Puri V. Inguinal hernias: should we repair? Surg Clin North Am 2008;88:127-38, ix. DOI PubMed

13. Chung L, Norrie J, O'Dwyer PJ. Long-term follow-up of patients with a painless inguinal hernia from a randomized clinical trial. $\mathrm{Br} J$ Surg 2011;98:596-9. DOI PubMed

14. Gong W, Li J. Operation versus watchful waiting in asymptomatic or minimally symptomatic inguinal hernias: The meta-analysis results of randomized controlled trials. Int J Surg 2018;52:120-5. DOI PubMed

15. Reistrup H, Fonnes S, Rosenberg J. Watchful waiting vs repair for asymptomatic or minimally symptomatic inguinal hernia in men: a systematic review. Hernia 2020. DOI PubMed

16. Ochoa-Hernandez A, Timmerman C, Ortiz C, Huertas VL, Huerta S. Emergent groin hernia repair at a County Hospital in Guatemala: patient-related issues vs. health care system limitations. Hernia 2020;24:625-32. DOI PubMed 